\title{
Experimental and Density Functional Theory Study of a New Dimer with Tetrasubstituted Cyclobutane Ring System Isolated from Psoralea plicata Seeds
}

\author{
Youssef Arfaoui $^{1,2}$, Abdullah Sulaiman Al-Ayed ${ }^{1}$, Ridha Ben Said ${ }^{1,2,3}$ \& Arafa I. Hamed ${ }^{1,4}$ \\ ${ }^{1}$ Department of Chemistry, College of Science and Arts at Ar-Rass, Qassim University, Ar-Rass, Kingdom of \\ Saudi Arabia \\ ${ }^{2}$ Unité Physico Chimie des Matériaux Condensés-UR11ES19 Département de Chimie Faculté des Sciences de \\ Tunis Université Tunis El Manar Campus Universitaire, MANAR II, Tunis \\ ${ }^{3}$ Laboratoire de Chimie et Physique Quantiques-UMR5626 Université Paul Sabatier Bat. 3R1b4, Toulouse Cedex, \\ France \\ ${ }^{4}$ Phytochemistry Laboratory, Botany Department, Faculty of Science, Aswan University, Aswan, Egypt \\ Correspondence: Arafa I. Hamed, Phytochemistry Laboratory, Botany Department, Faculty of Science, Aswan \\ University, Aswan 81528, Egypt. Tel: 2-97-348-0450. E-mail: arafahamed75@yahoo.com
}

Received: June 3, 2013 Accepted: July 29, 2013 Online Published: October 9, 2013

doi:10.5539/ijc.v5n4p73 URL: http://dx.doi.org/10.5539/ijc.v5n4p73

\begin{abstract}
A new cyclobutane ring system related to plicatin B has been isolated from the methanol soluble fraction of Psoralea plicata seeds and named as $\beta$-diplicatin B. In addition, the anti-repellent (-)-loliolide and phloretic acid ethyl ester [3-(4-hydroxyphenyl) propanoic acid ethyl ester) have been isolated from the same extract, their structures being determined on the basis of $1 \mathrm{D}\left({ }^{1} \mathrm{HNMR}\right.$ and $\left.{ }^{13} \mathrm{CNMR}\right)$ and 2D (DQF-COSY, HMQC and HMBC) NMR and mass spectra. Stereoisomers of $\beta$-diplactin B have been optimized by means of density functional theory using the hybrid functional B3LYP.
\end{abstract}

Keywords: Psoralea plicata seeds, cyclobutane ring, $\beta$-diplicatin B, NMR, DFT

\section{Introduction}

Many molecular properties of organic compounds, such as chemical reactivity, catalytic, biological, and pharmacological activities, are critically affected not only by their functional groups but also by their spatial position. Thus, the disclosure of the relative configuration has a great impact on the full understanding of their chemical behaviors. Different approaches to determine the exact structure and/or configuration of organic products have been devised (Seco et al., 2004; Nicolaou et al., 2005; Bifulco et al., 2007). Stereochemical information on organic compounds is usually derived from vicinal $\mathrm{H}, \mathrm{H}$ coupling constants. The values of cyclobutane system vary widely with overlapping ranges from cis to trans couplings (Fleming \& Williams, 1967). Psoralea plicata Del. (Syn $=$ Cullen plicatum Del.) is an Egyptian wild perennial plant and it is known in Arabic as Marmid (Täckholm, 1974). Genus Psoralea is one of the most popular traditional Chinese medicines and is officially listed in the Chinese Pharmacopoeia. It used for the treatment of enuresis, pollakiuria, weak kidney, and pain and cold in the waist and knees (Qiao et al., 2006a, 2006b). The wide use of the plant seeds as anthelmintic, diuretic, diaphoretic, tonic or an aphrodisiac against impotence and menstruation disorders; or externally the treatment of leucodermia, psoriases and leprosy in Indian folkloric remedy prompted worldwide investigation Psoralea spp. to isolate its active components (Perry \& Metzger, 1980).

In the previous publications, we have isolated many structurally different compounds from the aerial parts including (Perry \& Metzger, 1980; Hamed et al., 1997) and from seed extract; we were able to isolate a group of benzofuran glycosides (Hamed et al., 1999). By thorough chromatographic separation and purification, we obtained three more compounds 2, 3 and 4 .

B3LYP hybrid functional has been used in describing potential energy surfaces (PES) (Becke, 1993; Lee et al., 1988). The geometries of the five stereoisomers were fully optimized using analytic gradients. The harmonic vibrational frequencies of the stationary points of the PES have been calculated at the same level of theory in order 
to identify the local minima as well as to estimate the corresponding zero point vibrational energy (ZPE). A 6-31G (d,p) Basis Set was employed for each atom (Cimino et al., 2004).

\section{Materials and Methods}

\subsection{Plant Material}

The seeds of Psoralea plicata were collected from Aswan Governorate, South of Egypt in March 2010. The plant was identified by Dr. Hamed A. I. according to Täckholm (1974). The voucher specimen was deposited at the herbarium of the Botany Department, Faculty of Science, Aswan, Egypt.

\subsection{Extraction and Isolation}

The dried grinded seeds $(200 \mathrm{~g})$ were defatted with hexane and the residue was extracted with EtOH $80 \%$ three times, yielding $25 \mathrm{~g}$ of extract according Hamed et al. (1997). Four grams from ethanolic extract was applied into Sephadix LH-20 column $(50 \times 5 \mathrm{~cm})$ and eluted stepwise with $\mathrm{H}_{2} \mathrm{O}(\mathrm{P}-\mathrm{A}), 20 \%$ methanol (P-B), 40\% methanol (P-C), 75\% methanol (P-D) and 100\% methanol (P-E). Fraction P-E was slurred with silica gel and transferred to a silica gel column, previously packed by the wet method in hexan- $\mathrm{CHCl}_{3}(7: 3)$, starting elution with the same solvent system to give compound $4(15 \mathrm{mg})$ and $3(10 \mathrm{mg})$. Elution with Hexan- $\mathrm{CHCl}_{3}-\mathrm{MeOH}(3.5: 1.4: 0.1)$ gave compound $2(20 \mathrm{mg})$.

\section{Results and Discussions}

Compound 2, showed a molecular ion peak in the MS spectrum $[\mathrm{M}]^{+}, \mathrm{m} / \mathrm{z} 492$, suggesting the molecular formula $\mathrm{C}_{30} \mathrm{H}_{36} \mathrm{O}_{6}$. Its IR spectrum displayed absorption bands at 3420 and $1715 \mathrm{~cm}-1$, indicated the presence of hydroxyl and carbonyl functions respectively. The ${ }^{13} \mathrm{CNMR}$ spectrum indicated the presence of two molecules of plicatin $\mathrm{B}$ with the absence of the olefinic carbon signals (Perry \& Metzger 1980), which were replaced by four signals at $\delta$ $43.53,44.38,47.72$, and 48.92 characters of a cyclobutane structure. The cyclobutane structure confirmed by ${ }^{1} \mathrm{H}-{ }^{1} \mathrm{H}$ and ${ }^{1} \mathrm{H}-{ }^{13} \mathrm{C}$ COSY (Hodges \& Porte 1964). The remaining carbon signals disclosed the presence of four methyl groups at $\delta 17.76,17.83,25.71$ (two methyl); two O-methyl groups ( $\delta 52.04$ and 52.12); eight methines at $\delta 115.11,115.72,121.66,125.77,126.50,129.63$ and 130.59. Also, it showed signals of two carboxylic carbons at $\delta 173.28$ and eight quaternary carbons at $\delta 126.35,128.31,128.42,133.09,134.29,134.67,152.61$, and 153.67.

The ${ }^{1} \mathrm{HNMR}$ spectrum exhibited signals at $\delta 4.53(1 \mathrm{H}$, brd $J=6.05 \mathrm{~Hz}, \mathrm{Ar}-\mathrm{CH}-), 3.75(1 \mathrm{H}$, overlapped with other signals, Ar-CH-), 3.53 (1H, brd, $J=9.6 \mathrm{~Hz},-\mathrm{CH}-\mathrm{CO}-)$ and $3.39(1 \mathrm{H}$, brd, $J=9.7 \mathrm{~Hz},-\mathrm{CH}-\mathrm{CO}-)$ characteristic for four cyclobutane protons. The remaining proton signals disclosed the presence of six aromatic protons at $\delta$ 6.53-7.03; two methine protons ( $\delta 5.03$ and 5.31, each triplet); two tertiary $\mathrm{OH}(\delta 5.15$ and 5.31, each singlet); two methylene signals $(\delta 3.16$ and 3.33 , each $d, J=6.9 \mathrm{~Hz})$ and four singlet methyl signals $(\delta 1.69,1.72,1.75$, and 1.76$)$ which are typical for two molecules of plicatin B (1), i.e. dimer of plicatin B.

It has been stated that, from the magnitude of the vicinal coupling in cyclobutane ring, it might be possible to determine the stereochemistry of the substituents on the cyclobutyl ring by deriving the values of the cis- and trans-vicinal coupling from the analysis of the spectra. However, vicinal coupling in cyclobutane system has been found to be sensitive to substitutions and strain effects. Furthermore, they vary over a sufficient range, so that some overlap between the values occurs. Due to the presence of phenyl ring appear shifted the resonance signals of cis-vicinal protons to higher field than those of trans-vicinal (Fleming \& Williams, 1967; Chi et al., 1997). This is the first report to isolate such dimer from natural sources and we have given the name $\beta$-diplicatin B (2) (Figure 1).

The configuration analyses of the $\beta$-diplicatin-B prove the probability presence of five isomers (Figure 2 ). The relative stability of these sterioisomers was evaluated using DFT approach. All stereoisomer's were optimized using DFT/B3LYP/6-31G (d, p) and localized as a minimum in the PES. For each stereoisomer, harmonic vibrational frequencies were calculated to confirm that all configurations are stable. The relative energies as well as corrections of zero point energy (ZPE) and free energy of the five stereoisomers are gathered at table 2 . The structure of configurations $2 \mathrm{a}, 2 \mathrm{~b}, 2 \mathrm{c}, 2 \mathrm{~d}$ and $2 \mathrm{e}$ was illustrated in figures $2 \mathrm{and} 3$. DFT calculations give energies in the order $2 a<2 b<2 c<2 d<2 e$ at the same order of steric effects. The theoretical results to which we have succeeded, shows that the stereoisomer $2 \mathrm{a}$ is the most stable one. The calculated free energies indicated that compound 2a to be the most populated gas-phase stereoisomers $(99.94 \%$ at $298 \mathrm{~K})$. These interpretations are in good agreements with our experimental choice.

Compound 3, showed optical rotation, UV and IR spectra identical with those reported for (-)-loloilide (Hodges \& Porte, 1964; Tanaka \& Matsunga, 1989). Its mass spectrum can be used conveniently for its identification. A side from the molecular ion peak, characteristic fragment ion peak at m/z $181\left[\mathrm{M}-\mathrm{CH}_{3}\right]^{+}, 178\left[\mathrm{M}-\mathrm{H}_{2} \mathrm{O}\right]^{+}, 163$

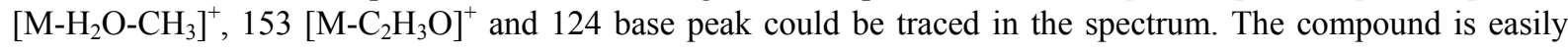
acetylated in the usual manner (pyridine/acetic anhydride, overnight), giving its acetate derivative as seen from the 
${ }^{1}$ HNMR spectrum of the acetate. The ${ }^{1} \mathrm{HNMR}$ spectrum of compound 3 is very informative, showing three quaternary methyl signals at $\delta 1.26,1.46$ and 1.80 and one methine proton broad singlet at $\delta$ 5.68. The remaining signals could be resolved through decoupling experiment. The ${ }^{13} \mathrm{CNMR}$ spectrum of compound 3 , allowed for simple assignment of its carbon skeleton and DEPT experiment displayed resonances at $\delta 182.34(\mathrm{~s}), 171.15(\mathrm{~s})$, $112.93(\mathrm{~d}), 86.61(\mathrm{~s}), 66.83(\mathrm{~d}), 47.31(\mathrm{t}), 45.63(\mathrm{t}), 30.63(\mathrm{q})$, and $27.00(\mathrm{q})$ and $26.49(\mathrm{q})$, confirming the structure of loliolide, a monoterpene lactone compound which has not been reported before from Psoralea plicata.<smiles>COC(=O)/C=C/c1ccc(O)c(CC=C(C)C)c1</smiles>
1<smiles>C[C@H]1CC(C)(C)C2=CC(=O)O[C@@]2(C)C1</smiles>

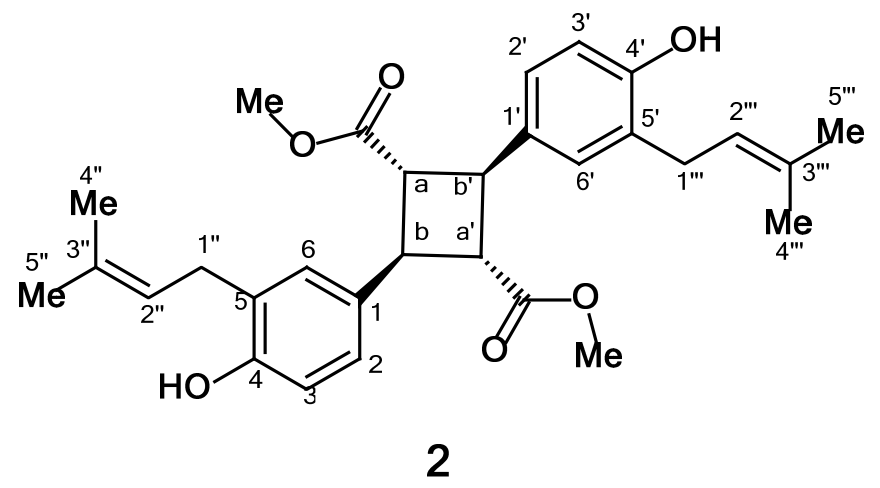<smiles>CCOC(=O)CCc1ccc(O)cc1</smiles>

4

Figure 1. Structures of compounds 1-4 


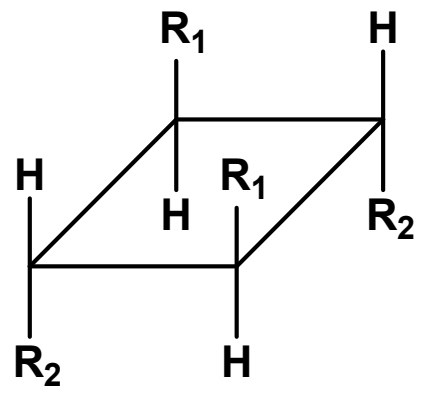

$2 a$

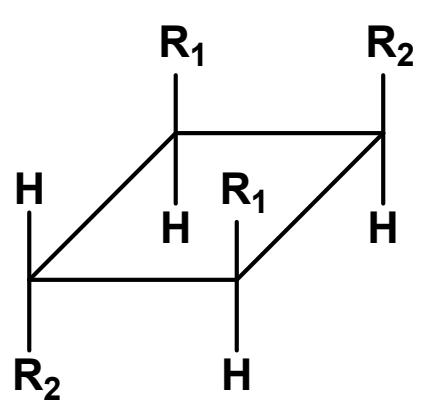

2c

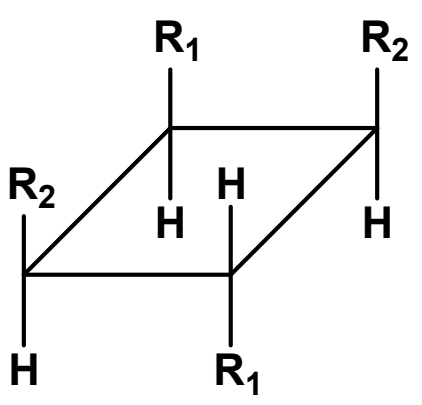

2d

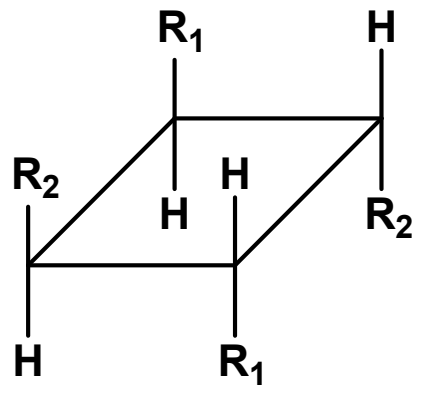

2b

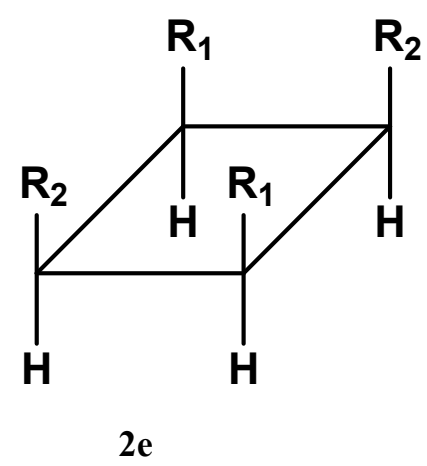

$R_{1}=$ 2-(3-methylbut-2-enyl)phenol

$\mathbf{R}_{\mathbf{2}}=$ methyl formate

Figure 2. Theoretical possible diastereomeric forms for the tetrasubstituted cyclobutane ring 


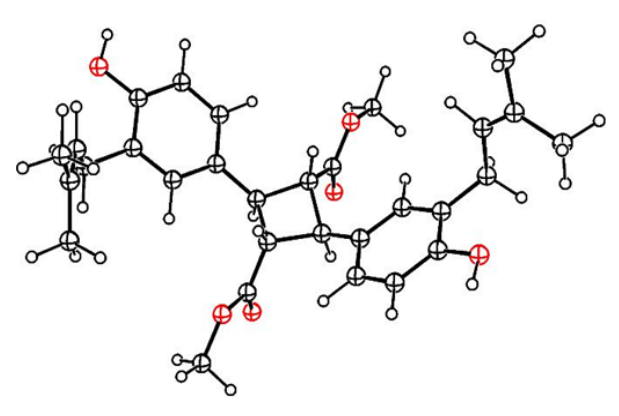

2a $(99.94 \%)$

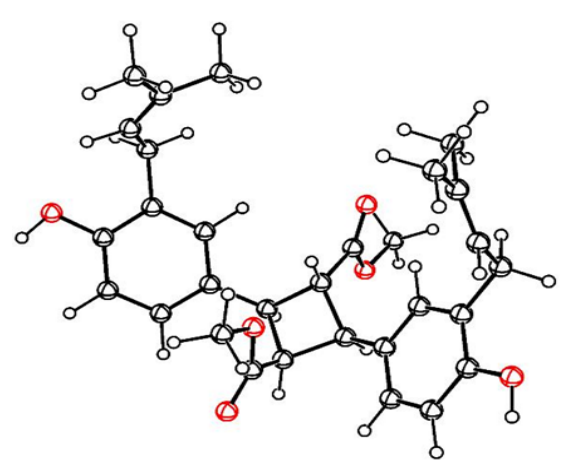

$2 \mathrm{c}(0.03 \%)$

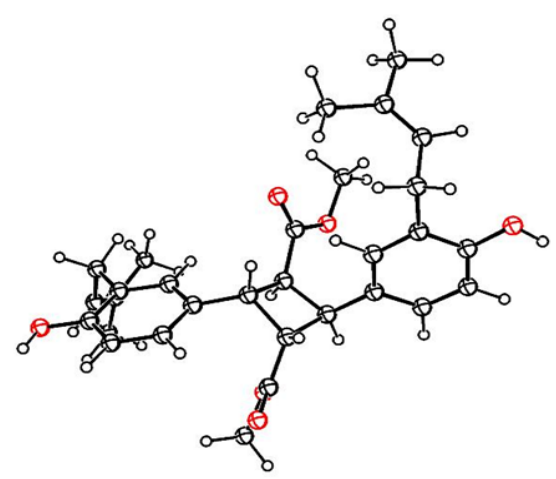

2b (0.03)

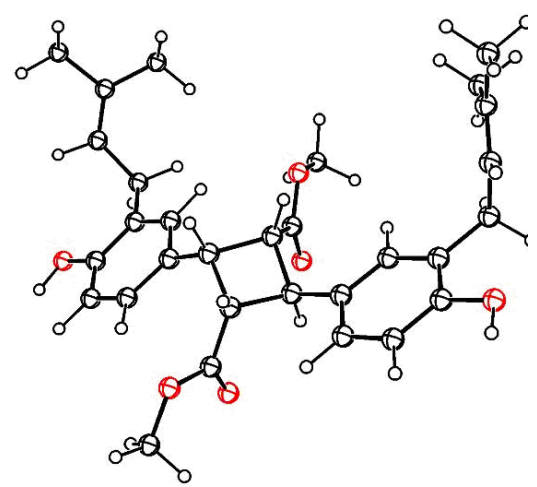

$2 d(0.00 \%)$

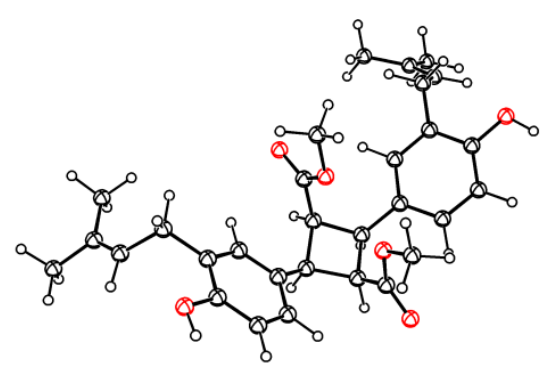

$2 \mathrm{e}(0.00 \%)$

Figure 3. Optimized geometries of five stereoisomer's of the calculated $\beta$-diplicatin B at the B3LYP/6-31(d,p) level. The values in parentheses are the calculated populations at $298 \mathrm{~K}$ in the gas phase for each streoisomer

Compound 4 showed molecular ion peak m/z (rel. int.) $194[\mathrm{M}]^{+}$, calculated for $\mathrm{C}_{11} \mathrm{H}_{14} \mathrm{O}_{3}$. The ${ }^{1} \mathrm{HNMR}$ spectrum exhibited two signals characteristic for $\rho$-substituted benzene ring at $\delta 6.76$ and 7.08 (each d, $J=8.56 \mathrm{~Hz}$ ); an AB quartet for two methylene protons at $\delta 4.23(2 \mathrm{H}, \mathrm{q}, J=7.06 \mathrm{~Hz})$; a triplet signal for one methyl group at $\delta 0.88(3 \mathrm{H}$, t, $J=7.03 \mathrm{~Hz})$ and two quartets at $\delta 2.85$ and $2.27(J=7.60 \mathrm{~Hz})$ assigned to two methylene groups adjacent to an ester function. The ${ }^{13} \mathrm{CNMR}$ spectrum showed resonances at $\delta 116.70$ (d), 130.81 (d), 128.70 (s), 174.41 (s), 42.31 
$(\mathrm{t}), 34.11(\mathrm{t}), 29.50(\mathrm{t})$, and $25.40(\mathrm{q})$. From the given data, compound 4 is supposed to be the ethyl ester of phloretic acid or 3(4-hydroxyphenyl)-propanoic acid, an acid isolated from the Heartwood of Haplomosia monophylla (Devon and Scott 1975), but this is the first report of isolation such ester from Psoralea plicata.

Table 1. ${ }^{1} \mathrm{H}$ NMR and ${ }^{13} \mathrm{C}$ NMR data of compound 2 in $\mathrm{CDCl}_{3}{ }^{\mathrm{a}}$

\begin{tabular}{cccccc}
\hline No. & ${ }^{1} \mathrm{H}-$ & ${ }^{13} \mathrm{C}-$ & No. & ${ }^{1} \mathrm{H}-$ & ${ }^{13} \mathrm{C}-$ \\
\hline 1 & ------- & $125.77(\mathrm{~s})$ & $1^{\prime}$ & ----- & $126.92(\mathrm{~s})$ \\
2 & $7.01(1 \mathrm{H}, \mathrm{brs})$ & $126.50(\mathrm{~d})$ & $2^{\prime}$ & $6.56(1 \mathrm{H}, \mathrm{brs})$ & $126.35(\mathrm{~d})$ \\
3 & ------ & $129.39(\mathrm{~s})$ & $3^{\prime}$ & ------ & $129.39(\mathrm{~s})$ \\
4 & ------ & $152.61(\mathrm{~s})$ & $4^{\prime}$ & ------ & $153.42(\mathrm{~s})$ \\
5 & $6.56(1 \mathrm{H}, \mathrm{d}, J=8.24 \mathrm{~Hz})$ & $115.11(\mathrm{~d})$ & $5^{\prime}$ & $7.29(1 \mathrm{H}, \mathrm{d}, J=8.51 \mathrm{~Hz})$ & $115.72(\mathrm{~d})$ \\
6 & $6.66(1 \mathrm{H}, \mathrm{dd}, J=8.24,2.53 \mathrm{~Hz})$ & $129.63(\mathrm{~d})$ & $6^{\prime}$ & $6.73(1 \mathrm{H}, \mathrm{dd}, J=8.51,1.01 \mathrm{~Hz})$ & $130.59(\mathrm{~d})$ \\
$1 "$ & $3.16(2 \mathrm{H}, \mathrm{d}, J=6.93 \mathrm{~Hz})$ & $29.53(\mathrm{t})$ & $1^{\prime \prime \prime}$ & $3.33(2 \mathrm{H}, \mathrm{d}, J=6.93 \mathrm{~Hz})$ & $29.78(\mathrm{t})$ \\
$2^{\prime \prime}$ & $5.08(1 \mathrm{H}, \mathrm{m})$ & $121.66(\mathrm{~d})$ & $2^{\prime \prime \prime}$ & $5.31(1 \mathrm{H}, \mathrm{m})$ & $121.75(\mathrm{~d})$ \\
$3 "$ & ------- & $134.29(\mathrm{~s})$ & $3^{\prime \prime \prime}$ & ------- & $134.67(\mathrm{~s})$ \\
$4 "$ & $1.69(3 \mathrm{H}, \mathrm{s})$ & $17.76(\mathrm{q})$ & $4^{\prime \prime \prime}$ & $1.75(3 \mathrm{H}, \mathrm{s})$ & $17.83(\mathrm{q})$ \\
$5 "$ & $1.72(3 \mathrm{H}, \mathrm{s})$ & $25.71(\mathrm{q})$ & $5^{\prime \prime \prime}$ & $1.76(3 \mathrm{H}, \mathrm{s})$ & $25.71(\mathrm{q})$ \\
$\mathrm{C}=\mathrm{O}$ & ------ & $173.28(\mathrm{~s})$ & $\mathrm{C}=\mathrm{O}$ & ------ & $173.28(\mathrm{~s})$ \\
$\mathrm{a}$ & $3.75(J=9.60 \mathrm{~Hz})$ & $44.38(\mathrm{~d})$ & $\mathrm{a}^{\prime}$ & $3.39(J=9.60 \mathrm{~Hz})$ & $43.35(\mathrm{~d})$ \\
$\mathrm{b}$ & $4.82(J=6.05 \mathrm{~Hz}$ & $48.92(\mathrm{~d})$ & $\mathrm{b}^{\prime}$ & $4.53(J=6.05 \mathrm{~Hz})$ & $47.72(\mathrm{~d})$ \\
$\mathrm{OMe}$ & $3.72(3 \mathrm{H}, \mathrm{s})$ & $52.12(\mathrm{q})$ & $\mathrm{OMe}$ & $3.73(3 \mathrm{H}, \mathrm{s})$ & $52.12(\mathrm{q})$ \\
\hline
\end{tabular}

${ }^{a}$ Assignments were confirmed by DQF-COSY, HMQC and DEPT experiments.

Table 2. DFT/B3LYP relative energies as well as corrections of zero point energy (ZPE) and free energy (kcal mol-1) of the five stereoisomers

\begin{tabular}{cccccc}
\hline & $2 \mathrm{a}$ & $2 \mathrm{~b}$ & $2 \mathrm{c}$ & $2 \mathrm{~d}$ & $2 \mathrm{~d}$ \\
\hline$\Delta \mathrm{E}$ & 0.0 & 4,1 & 3,8 & 9,6 & 15,0 \\
$\Delta \mathrm{E}+\mathrm{ZPE}$ & 0.0 & 4,3 & 4,0 & 9,7 & 15,2 \\
$\Delta \mathrm{G}^{\circ}$ & 0.0 & 4,9 & 4,8 & 10,7 & 16,8 \\
\hline
\end{tabular}

Compound 2 ( $\beta$-diplicatin B): Colourless viscous liquid; $[\alpha]_{\mathrm{D}}-15.2\left(\mathrm{c}=0.23 \mathrm{CHCl}_{3}\right)$; IR spectrum $\mathrm{v}_{\text {max }} \mathrm{cm}^{-1}: 3420$ $(\mathrm{OH}), 1715(\mathrm{C}=\mathrm{O}), 1590,860$ and 820 (1, 3, 4-trisubstitued benzene ring); EIMS m/z: $492[\mathrm{M}]^{+}$(10) calculated for $\mathrm{C}_{30} \mathrm{H}_{36} \mathrm{O}_{6}, 245\left[\mathrm{M}-\mathrm{C}_{15} \mathrm{H}_{17} \mathrm{O}_{3}\right]^{+}$(35). ${ }^{1} \mathrm{HNMR}(400 \mathrm{MHz})$ and ${ }^{13} \mathrm{CNMR}(100 \mathrm{MHz})$ as given in (Table 1).

Compound 3 (liliolide): colourless crystals; $\mathrm{mp} .149-150{ }^{\circ} \mathrm{C} ;[\alpha]_{\mathrm{D}}-150\left(\mathrm{c}=0.23 \mathrm{CHCl}_{3}\right)$; IR spectrum $\mathrm{V}$ max cm-1: $3430(\mathrm{OH}), 1735(\mathrm{C}=\mathrm{O})$; EIMS m/z: $196[\mathrm{M}]^{+}$(32) calculated for $\mathrm{C}_{15} \mathrm{H}_{17} \mathrm{O}_{3}, 178[\mathrm{M}-\mathrm{H} 2 \mathrm{O}]^{+}(50), 163$ [M-H2O-CH3] ${ }^{+}$(20), 140 (45), 124 (100), 112 (94), 91 (54), 66 (48).

Compound 4 (phloretic acid ethyl ester): EIMS m/z: $194[\mathrm{M}]^{+}$(50) calculated for $\mathrm{C}_{11} \mathrm{H}_{14} \mathrm{O}_{3},{ }^{13} \mathrm{CNMR}$ spectrum: $116.71(d), 130.80$ (d), $128.74(\mathrm{~s}), 157.72(\mathrm{~s}), 173.40(\mathrm{~s}), 42.33(\mathrm{t}), 34.11(\mathrm{t}), 29.50(\mathrm{t})$, and $25.41(\mathrm{q})$.

\section{References}

Becke, A. D. (1993). Density-functional thermochemistry III. The role of exact exchange. J. Chem. Phys., 98, 5648. http://dx.doi.org/10.1063/1.464913

Bifulco, G., Dambruoso, P., Gomez-Paloma, L., \& Riccio, R. (2007). Determination of relative configuration in organic compounds by NMR spectroscopy and computational methods. Chem. Rev., 107, 3744-3779. http://dx.doi.org/10.1021/cr030733c 
Boardely, M., Stirton, C. H., \& Harborne, J. B. (1986). A chemotaxonomic survey of the tribe Psoraleeae in Africa. Biochemical Systematics and Ecology, 14(6), 603-613. http://dx.doi.org/10.1016/0305-1978(86)90041-4

Chi, Y. M., Hashimoto, F., Yan, W. M., \& Nohara, T. (1997). Four monoterpene alkaloid derivatives from Incarvillea sinensis. Phytochemistry, 46(4), 763-769. http://dx.doi.org/10.1016/S0031-9422(97)89084-X

Cimino, P., Gomez-Paloma, L., Duca, D., Riccio, R., \& Bifulco, G. (2004). Comparison of different theory models and basis sets in the calculation of 13C NMR chemical shifts of natural products. Magn. Reson. Chem., 42, 26-33. http://dx.doi.org/10.1002/mrc.1410

Devon, T. K., \& Scott, A. I. (1975). Handbook of Naturally Occurring Compounds. New York, London: Academic Press.

Fleming, I., \& Williams, D. H. (1967). The NMR spectra of four membered carbocyclic ring systems. Tetrahedron, 23, 2747-2752. http://dx.doi.org/10.1016/0040-4020(67)85140-8

Hamed, A. I., Springuel, I., \& El-Emary, N. A. (1999). Benzofuran glycosides from Psoralea plicata. Phytochemistry, 50, 887-890. http://dx.doi.org/10.1016/S0031-9422(98)00521-4

Hamed, A. I., Springuel, I., El-Emary, N. A., Mitome, H., \& Yamada, Y. (1997). Phenolic cinnamate dimer from Psoralea plicata. Phytochemistry, 45, 1257-1261. http://dx.doi.org/10.1016/S0031-9422(97)00105-2

Hodges, R., \& Porte, A. L. (1964). The structure of loliolide: A terpene from Lolium perenne. Tetrahedron, 20 , 1463-1467. http://dx.doi.org/10.1016/S0040-4020(01)99140-9

Lee, C., Yang, W., \& Parr, R. G. (1988). Development of the Colle-Salvetti conelation energy formula into a functional of the electron density. Phys. Rev. B, 37, 785. http://dx.doi.org/10.1103/PhysRevB.37.785

Montaudo, G., \& Caccamese, S. (1974). Photodimers of cinnamic acid and related compounds: A stereochemical study by NMR. Organic Chemistry Resonance, 6, 534-536. http://dx.doi.org/10.1002/mrc.1270061006

Nicolaou, K. C., \& Snyder, S. A. (2005). Chasing molecules that were never there: misassigned natural products and the role of chemical synthesis in modern structure elucidation. Chem. Int. Ed., 44, 1012-1044. http://dx.doi.org/10.1002/anie.200460864

Perry, L. M., \& Metzger, J. (1980). Medicinal plants of East and South-East Asia: Attributed properties and uses (p. 224). Cambridge, MA: The MIT Press.

Qiao, C. F., Han, Q. B., Mo, S. F., Song, J. Z., Xu, L. J., Chen S. L., . . Xu, X. H. (2006a). Psoralenoside and isopsoralenoside, two new benzofurn glycosides from Psoralea corylifolia. Chemical Pharmaceutical Bulletin, 54(5), 714-716. http://dx.doi.org/10.1248/cpb.54.714

Qiao, C. F., Han, Q. B., Mo, S. F., Song, J. Z., Xu, L. J., Chen, S. L., . . Xu, X. H. (2006b). Quality assessment of fructus Psoraleae. Chemical Pharmaceutical Bulletin, 54(6), 887-890. http://dx.doi.org/10.1248/cpb.54.887

Seco, J. M., Quiñoà, E., \& Riguera, R. (2004). The assignment of absolute configuration by NMR. Chem. Rev., 104, 17-118. http://dx.doi.org/10.1021/cr000665j

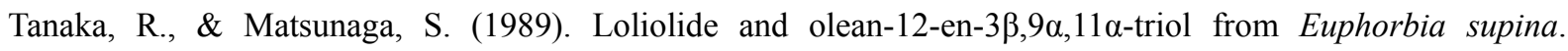
Phytochemistry, 28, 1699.

Täckholm, V. (1974). Students' Flora of Egypt (2nd ed.). Publishing by Cairo University, Printed by Cooperative Printing Company, Beirut.

\section{Copyrights}

Copyright for this article is retained by the author(s), with first publication rights granted to the journal.

This is an open-access article distributed under the terms and conditions of the Creative Commons Attribution license (http://creativecommons.org/licenses/by/3.0/). 